\title{
Introduction to Special Issue: National Research Center for Distance Education and Technological Advancements (DETA)
}

\author{
Tanya Joosten \\ Director of Digital Learning Research and Development, \\ Co-Director, National Research Center for Distance Education and Technological Advancements \\ University of Wisconsin-Milwaukee
}

This issue of $O L J$ includes four articles from a submission process resulting from invitations to participants in research supported by the National Research Center for Distance Education and Technological Advancements (DETA). These projects were funded under Grant \#84.116Q, P116Q140006, from the U.S. Department of Education's Fund for the Improvement of Postsecondary Education. The objective of the DETA Research Center is to promote student access and success through evidence-based online learning practices and learning technologies. Specifically, DETA identifies and evaluates instructional and institutional practices, with particular attention to underrepresented individuals (i.e., Pell Grant eligible, first-generation college, minorities, and students with disabilities), through rigorous research.

These articles discuss a broad range of interests relating to distance education, including blended and online learning, and competency-based education. These studies address academic and social interactions, instructional characteristics or design elements of courses (including student-created content), and their relationships to student success. They also evaluate the efficacy of competency-based education.

The first of our articles is "Perceptions of the Persistent: Engagement and Learning Community in Underrepresented Populations" by Wendy Athens of Utah Valley State. A key area of focus for online learning research seeks to identify social and academic interactions that can increase student success. This interest includes understanding the relationship between engagement and student outcomes. In this paper, the author explores engagement and learning community to establish a baseline to which future instructional design and retention efforts can be compared. The paper investigates how online student success (as measured by grades) is related to student perceptions of engagement and learning community. Instrumentation for engagement and learning community were gathered using reliable measures from the DETA Research Toolkit (http://www.uwm.edu/deta). Also, the investigation examines variation across subpopulations. The author concludes that engagement and learning community are positively related to student success for the entire population and the subpopulation. Other findings are discussed, including additional subpopulation analyses. This study provides insights related to academic and social interactions and student success, which could lead to identifying ways to better engage learners in online courses. The author concludes that online course activities that enhance engagement and learning community may positively influence student success. 
The second of our articles is "Do Student-Produced Videos Enhance Engagement and Learning in the Online Environment" by Denise Stanley and Jenny Zhang from California State University-Fullerton. Again, engagement strategies are deemed important in online courses. In this paper, the authors explore the engagement strategy of using student-produced activities. The paper investigates how student-generated videos increase student engagement and improve learning outcomes. Also, it investigates differences between groups of students with varied demographic backgrounds. The authors conclude that student-produced activities, such as student podcasting and video production, improve engagement and learning. Better class performance and learning gains are reported in the treatment section compared with the control section. This study provides insights into the impact of student-created content, especially in regard to the increase in mastery of specific concepts related to that content. The authors find that courses incorporating studentcreated content, such as videos, may increase engagement and learning. Details of the studentproduced video activity are included.

The third of our articles is "Exploring Best Practices for Online STEM Courses: Active Learning, Interaction \& Assessment Design" by Baiyun Chen, Kathleen Bastedo, and Wendy Howard Mail of the University of Central Florida. Online education in science, technology, engineering, and mathematics (STEM) is quickly evolving, and instructional staff are identifying how to best design STEM online courses. In this paper, the authors explore course design elements of active learning, interactivity, and assessment. The paper investigates the frequency of the presence of these design elements and their relationship to student outcomes of learning and satisfaction. The authors conclude that courses should be designed to engage students with reallife problems and active learning experiences, with a variety of additional instructional resources and student collaboration opportunities to ensure clarity of instruction, and with considerations for accessibility. This study provides insights that will inform designers and instructors how to design effective online STEM courses.

The final article in this special edition is "An Evaluation of Critical Thinking in Competency-Based and Traditional Online Learning Environments" by Matthew Mayeshiba, Kay Jansen, and Lisa Mihlbauer. New approaches to developing online courses and programs are evolving to better meet the needs of students in completing their degrees. Competency-based education (CBE) that is offered online and is designed as a nonterm, direct assessment program is one of those approaches. Researchers are identifying ways to determine the efficacy of these new programs. In this paper, the authors compare students' critical thinking between a traditional online program and a nonterm, direct assessment CBE program. The paper investigates whether CBE students demonstrate critical thinking at levels similar to those demonstrated by students enrolled in the traditional online environment. Assessments were scored using the Valid Assessment of Learning in Undergraduate Education (VALUE). The authors conclude that the two environments demonstrated student critical thinking at comparable levels. This study provides insight to the efficacy of nonterm, direct assessment CBE program. 